\section{Crossroads or threshold? Sport and exercise medicine as a specialty in the UK}

\author{
Michael Cullen
}

How successful have we been in developing the specialty of sport and exercise medicine? Dr Pigozzi's article on the development of Sports Medicine in Europe caused me to sit back and examine how Sport and Exercise Medicine (SEM) has progressed in the United Kingdom since first being declared a medical specialty in 2005. (see page 1085) At that time Mark Batt and I described the path to specialty recognition and concluded that there was considerable work to be done to ensure that SEM became an integral and essential component of the National Health Service. ${ }^{2}$

Following recognition as a specialty and the subsequent creation of a Faculty of Sport and Exercise Medicine (FSEM UK), there has been considerable time and energy expended to create the infrastructure to develop and promote SEM. The original specialty training curriculum was approved in 2007 and sets out the knowledge, skills and experiences expected of a doctor completing specialty training (www.jrcptb.org.uk/ Specialty/Pages/SportandExerciseMedicine. aspx). It has recently been rewritten (along with all other medical specialties) to conform to the revised standards of training and assessments set out by the Postgraduate Medical Education and Training Board and will become operative in 2010.

Training posts in SEM commenced in 2007 and at present there are approximately 30 doctors undergoing higher specialty training; recent Department of Health funding will increase this number to more than 50 within the current financial year. Training programmes are currently being delivered in most regions in England and in all of the devolved administrations (Scotland, Wales and Northern Ireland). Responsibility for ensuring the quality of training within the UK lies with the Specialist Advisory Committee of FSEM. Doctors enter specialty training having completed

Correspondence to: Professor Michael Cullen, Musgrave Park Hospital Consultant in Sports Medicine, Stockmans Lane, Belfast BT9 7JB, UK; michael. cullen747@btinternet.com
2 years of Foundation training and at least a further 2 years training in General Medicine, General Practice or Emergency Medicine. The higher specialty training programme in SEM is of 4 years' duration and leads to inclusion on the Specialist Register of the General Medical Council, a requirement for appointment as a consultant within the UK's National Health Service.

Given the progress detailed above, why is our specialty at a crossroads or threshold? At present we have established training programmes with highly qualified and motivated trainees. Our first accredited specialists are emerging into the workplace - and that is where the "crossroads" arises. To date there have been no substantive NHS consultant posts available for these doctors. The challenge now facing the specialty is to persuade the Department of Health and local healthcare commissioners that SEM specialists can provide a valuable and effective service, not only in treating the injuries arising from participation in sport, but also as central figures in the multi-agency and multidisciplinary fight against the rising tide of medical problems associated with physical inactivity.

However, with every challenge comes opportunity - hence the "threshold". Having recently attended the BASEM Annual Congress in Edinburgh, I was struck by the energy, enthusiasm and determination of the doctors entering our specialty. High-level discussions are currently taking place with the Department of Health and I am optimistic that a number of consultant posts will be funded. I have no doubt that, once a few such posts are established, the true value of SEM will quickly become apparent and many others will follow. Indeed, the paper by O'Halloran and colleagues in this issue of BJSM demonstrates that there is already recognition from other medical specialists of the potential role of SEM within the NHS. ${ }^{4}$ (see page 1143) As this survey was conducted in 2007, when training programmes were only just being created, there is reason to suppose that there would be even greater awareness if this were repeated today. I firmly believe that SEM in the UK is very much on the threshold rather than at the crossroads on its journey to become an established NHS specialty.

\section{EXERCISE AS MEDICINE}

The specialty curriculum for SEM in the UK differs somewhat from that of other countries in its emphasis on the role of exercise as a driver for health and in the management of chronic disease. At present only $40 \%$ of adult males and $28 \%$ of adult females in the UK are physically active enough to benefit health. This journal champions the "Exercise as Medicine" message, ${ }^{5}$ and in the current issue Hamer and colleagues report that even low levels of physical activity promote mental health. ${ }^{6}$ (see page 1111) Emphasising the causal link, there was a dose-dependent response with greater benefits for those undertaking higher exercise loads. A recent paper published in the $B M J$ highlighted the link between mental illness and obesity, noting that common mental disorders were associated with an increased risk of obesity, and that the risk of obesity increased with the number of episodes of depression or anxiety. ${ }^{7}$ Obesity and its associated morbidities place enormous strain on our healthcare resources. Recent Government figures predict that, if the prevalence of obesity continues to rise at its current rate, nine out of 10 adults and two out of three children in the UK will be obese by 2050 - a frightening prospect. $^{8}$

The promotion of physical activity should be an essential element of any management strategy for these and many other medical problems. Buffort and colleagues report from Australia on changes over the past 10 years in GPs' perspectives and practices of physical activity counselling. ' (see page 1149) There was a significant increase in the number of GPs who felt confident in giving exercise advice (and indeed felt it was their role to do so) but this change occurred between 1997 and 2000 and plateaued thereafter. Thus, physical activity counselling had not become a routine practice for many, and the authors conclude that GPs could play a much greater role in this aspect of health promotion. A case of "good, but could do better" or perhaps an example 
of how a SEM physician could be utilised to complement and underpin the initiatives currently available in primary care?

\section{AND FINALLY — TENDINOPATHY}

The management of tendinopathy continues to be a major challenge for SEM physicians. The relationship of the characteristic histological and imaging features of tendinosis to pain and dysfunction remains uncertain. A further paper from Sweden (see page 1136) examines the presence of neuropeptide $\mathrm{Y} 1$ in tenocytes and blood vessel walls from normal and abnormal (tendinosis) Achilles tendons and suggests a potential future treatment pathway for these conditions - watch this space. ${ }^{10}$

Competing interests: None.

Provenance and peer review: Commissioned; not externally peer reviewed.

Accepted 26 October 2009

Br J Sports Med 2009;43:1083-1084.

doi:10.1136/bjsm.2009.069187

\section{REFERENCES}

1. Pigozzi $\mathbf{F}$. The Specialisation in Sports Medicine in Europe: State of the art and the Sports Medicine Specialty Training Core Curriculum in the EU. $\mathrm{Br} J$ Sports Med 2009;43:1085-7.

2. Cullen M, Batt M. Sport and Exercise Medicine in the United Kingdom comes of age. Br J Sports Med 2005:39:250-1.

3. Blair SN. Physical inactivity: the biggest public health problem of the 21st century. Br J Sports Med 2009;43:1-2.

4. O'Halloran P, Tzortziou Brown V, Morgan K, et al. The Role of the Sport and Exercise Medicine Physician in the National Health Service: A questionnaire-based survey. Br J Sports Med 2009;43:1143-8.

5. Sallis RE. Exercise is medicine and physicians need to prescribe it! Br J Sports Med 2009;:43:3-4.

6. Hamer M, Stamatakis E, Steptoe A. Dose response relationship between physical activity and mental health: The Scottish Health Survey Br J Sports Med 2009;43:1111-4.

7. Kivimäki M, Lawlor DA, Singh-Manoux A, et al. Common mental disorder and obesity insight from four repeat measures over 19 years: prospective Whitehall II cohort study. BMJ 2009;339: 902-5.

8. Foresight. Tackling Obesities: Future Choices Project Report. Government Office for Science, 2007.

9. Buffart L, Van der Ploeg H, Smith B, et al. General practitioners perceptions and practices of physical activity counselling: changes over the past 10 years Br J Sports Med 2009;43:1149-53.

10. Bjur D, Alfredson H, Forsgren S. Presence of neuropeptide $Y 1$ receptor in tenocytes and blood vessel walls in the human Achilles tendon $\mathrm{Br} J$ Sports Med 2009:43:1136-42. 